\title{
Evaluation of the primary care for chronic diseases in the high coverage context of the Family Health Strategy
}

Kelly Cristina Gomes Alves ${ }^{1,2^{*}+}$ (D), Rafael Alves Guimarães ${ }^{1}$, Marta Rovery de Souza ${ }^{1}$ and Otaliba Libânio de Morais Neto ${ }^{1+}$

\begin{abstract}
Background: This cross-sectional study evaluated the adequacy of the Family Health Strategy for the primary care model for chronic noncommunicable diseases and the changes that occurred between the two cycles of external evaluations of the National Program for Improving Access and Quality of Primary Care, which took place in 2012 and 2014, in the higher coverage context of the Family Health Strategy of Brazil, in the state of Tocantins, Brazil.

Methods: The data source contained information on the infrastructure of the 233 Primary Health Units and on the work process of 266 health teams. The Principal Component Analysis for Categorical Data technique and the McNemar chi-squared statistical test for comparing paired samples were used, and a significance level of $5 \%$ with a 95\% Confidence Interval was used.

Results: The analysis identified a low proportion of dispensing of medications for the treatment of chronic disease in both cycles. There was a significant increase in seasonal influenza vaccination, in the number of sterilization, procedure, dressings and inhalation rooms. There was a small but significant reduction in the materials for cervical cancer screening, although they are available in almost $90.0 \%$ of the PHUs. More than $70.0 \%$ of the health teams carried out additional health education activities, encouraged physical activity, registered schoolchildren with health needs for monitoring, evaluated user satisfaction and user referral.

Conclusions: The findings of this study highlighted the improvement of the structure of the Primary Health Units, but identified a low provision of medicines to treat chronic diseases. The health promotion was performed as the main work process tool of family health teams, but it was little focused on intersectoral actions and on actions with the population in the area or on the empowerment of users through self-management support for chronic diseases. Furthermore, it is critical that the Family Health Strategy in Tocantins be organized and focused on the care of chronic diseases to improve and adapt itself to a primary chronic care model.
\end{abstract}

Keywords: Primary health care, Family practice, Primary care model, Noncommunicable disease, Chronic diseases, Chronic care model, Evaluation of care, Quality of care, Brazil

\footnotetext{
* Correspondence: kellygomesalves@gmail.com

${ }^{1}$ Institute of Tropical Pathology and Public Health, Federal University of Goiás,

Goiânia, Goiás, Brazil

${ }^{2}$ Department of Medicine, Federal University of Tocantins, Palmas, Brazil
}

(c) The Author(s). 2019 Open Access This article is distributed under the terms of the Creative Commons Attribution 4.0 International License (http://creativecommons.org/licenses/by/4.0/), which permits unrestricted use, distribution, and reproduction in any medium, provided you give appropriate credit to the original author(s) and the source, provide a link to the Creative Commons license, and indicate if changes were made. The Creative Commons Public Domain Dedication waiver (http://creativecommons.org/publicdomain/zero/1.0/) applies to the data made available in this article, unless otherwise stated. 


\section{Background}

Noncommunicable diseases (NCDs) were responsible for 41 million (71.0\%) deaths worldwide in 2016, with four main groups of causes: cardiovascular diseases (44.0\%), neoplasms $(22.0 \%)$, chronic respiratory diseases $(9.0 \%)$ and diabetes (4.0\%); approximately $44.0 \%$ of these deaths occurring in people between 30 and 70 years of age. More than $80.0 \%$ of these premature deaths occurred in low- and middle-income countries where the disease burden is greater, resulting in large economic losses for the countries. Premature deaths can be avoided by reducing the major modifiable risk factors, such as smoking, harmful alcohol use, unhealthy eating and physical inactivity [1]. In Brazil, proportional mortality due to NCDs was responsible for $59.6 \%$ of all deaths in 1990 , $72.0 \%$ in 2011 and $75.8 \%$ in 2015 [2, 3]. Almost half of the Brazilian population (45.1\%) reported having at least one chronic disease, with hypertension being the most frequently mentioned disease $(21.4 \%)$ in the National Health Survey (Pesquisa Nacional de Saúde), conducted in 2013 throughout Brazil [4].

The World Health Organization [1] proposed a set of systematized interventions in the Global Plan to combat NCDs and reduce these deaths, with the goal of reducing them by one-third by 2030. The Plan proposes the strengthening of a health system directed toward integral care for people with NCDs. This plan especially includes the restructuring of Primary Health Care, the purpose of which is prevention, early detection, appropriate treatment, reduction of the main factors, risk management and the continued management of cases and people at high risk for major diseases; the goal of these aims is to prevent complications such as hospitalizations and premature deaths, as well as reduce financial expenses [5].

In Brazil, since the creation of the Brazilian Nation Health System (Sistema Único de Saúde - SUS) in 1988, the structuring and expansion of Primary Health Care has been carried out through the Family Health Strategy (FHS). The FHS performs activities through family health teams in Primary Health Units (PHUs) aimed at serving the target population living near the PHUs, known as ascribed population [6]. Substantial investments at the federal, state and municipal levels have led to a progressive increase in family health teams, with a population coverage in the country of $53.4 \%$ in 2013 . The state of Tocantins, in the northern region of the country, has the highest coverage (93.6\%) among the Brazilian states [7].

In 2011, the Strategic Action Plan to Tackle Chronic Noncommunicable Diseases in Brazil 2011-2022 was instituted, with three important intervention axes: surveillance, information, evaluation and monitoring; health promotion; and integral care [8]. In the same year, to promote the expansion of coverage and increase the scope of the Primary Health Care actions [9], the National Primary Care Policy (Politica Nacional de Atenção Básica) was updated, emphasizing the prevention and organization of primary care for NCDs patients [6]. In this context, the National Program for Improving Access and Quality of Primary Care (Programa Nacional de Melhoria do Acesso e da Qualidade da Atenção Básica PMAQ-AB) was created with the aim of evaluating and promoting the improvement of Primary Health Care through changing the healthcare model, with an emphasis on prevention and integral care for NCDs [10]. The PMAQ-AB has national coverage, is linked to financial incentives for municipal management with the adhesion of family health teams to the Program and has three phases: adherence and contracting (phase 1), certification (phase 2) and recontracting (phase 3). In phase 2 , the external evaluation is responsible for collecting data on the PHUs infrastructure, disease prevention, health promotion and clinical management of various diseases, including NCDs, as well as user satisfaction [11].

The PMAQ-AB is a data source with great potential to assess the capacity of the health teams to tackle NCDs in the Primary Health Care context. Furthermore, it may be a data source that can be used to assess the adequacy of the strategies used in the FHS according to the theoretical model of chronic care, such as the chronic care model proposed by Wagner [12]. Although the PMAQ$\mathrm{AB}$ has not been structured to exclusively evaluate health actions directed toward NCDs, it is important to verify whether the variables contained in it allow the essential elements of a primary care model for NCDs to be evaluated, as well as the identification of those that better explain this model. It is also important to determine whether there were improvements in primary care for NCDs after the interventions of the PMAQ-AB and which variables are more capable of identifying the changes between the cycles that were evaluated. The aim of this study was to evaluate the adequacy of the structure of PHUs and the work process of family health teams in the FHS according to the primary care model for NCDs and also to examine the changes that occurred between the two cycles of external evaluations of the PMAQ-AB, which took place in 2012 and 2014, in the FHS of the state of Tocantins, Brazil.

\section{Methods \\ Study design and population}

This was a cross-sectional analytical study in which the data source was the national database of the PMAQ-AB, which contains information on the infrastructure of the PHUs and the work process of the family health teams. This database was generated by data collection from the external evaluation, phase 2 of the Program, based on 
two cross-sectional studies conducted in Cycle 1 and Cycle 2, in 2012 and 2014, respectively. Data collection in both cycles was managed by the general coordinator of the program located in the Primary Care Department (Departamento de Atenção Básica - DAB) of the Ministry of Health in partnership with several teaching and research institutions in Brazil. The coordination of the data collection in the state of Tocantins was performed by Fiocruz-Rio de Janeiro, and the local coordination of the two cycles was delegated to the first author of this article. The national studies were approved under authorization No. 32012/2012 and No 357.974/2013 of the Research Ethics Committee of the National School of Public Health.

The state of Tocantins is the newest of the 26 states in Brazil, has 139 municipalities and is located in the Northern Region. It is part of the Amazon region, has extensive rural areas with a low population density and was one of the states with the highest adherence to the PMAQ-AB in Cycle 1 and Cycle 2. There were 400 family health teams in July 2012 and 475 teams in July 2014 [13]. The study population was composed of the PHUs and family health teams that adhered to the PMAQ-AB in both Cycle 1 and Cycle 2. In Cycle 1, 291 PHUs were studied, and 306 teams were interviewed, with 261 PHUs and 361 teams in Cycle 2. After the exclusion of the PHUs and teams that did not participate in both cycles, 233 PHUs and 266 teams working in 90 (64.75\%) municipalities of the state that participated in the two cycles were included in the data analysis of this study.

Logical model, data collection and selection of the variables To date, the PMAQ-AB has submitted three external evaluation cycles for the years 2012, 2014 and 2017, and the data for Cycle 1 and Cycle 2 are already available in the DAB database. Its data collection instruments are composed of three modules, which are broken down as follows: module I - observation in the PHUs regarding the infrastructure, equipment, materials and inputs; module II - interview with professionals at the PHUs regarding the performance of the family health teams in the dimensions of Primary Health Care management, health promotion, prevention and integral care for users; and module III - interview with users at the PHUs regarding their satisfaction with the care received. Other modules were incorporated after Cycle 1. In this study, the first two modules were considered.

Although PMAQ-AB has not been structured to exclusively evaluate health actions focused on NCDs, it is a data source with great potential for assessing primary care for NCDs in the FHS and it is the largest national database for assessing FHS. To evaluate the adequacy of primary care for the NCDs care performed by the FHS teams, from the data contained in modules I and II of the PMAQ-AB, a logic evaluation model was constructed. This logical model used the health service evaluation models proposed by Donabedian [14], the chronic care model of Wagner [12] and the model of Hartz and da Silva [15] as the theoretical framework. The logical model developed for the study (Fig. 1) consists of the following components: (i) structure of the PHUs, (ii) work process of the family health teams, and (iii) outcomes based in the organization of the family heath teams [14]. This study prioritized the evaluation of the adequacy of the primary care provided by the FHS teams directed toward NCDs using the framework of Wagner [12] systematized in the chronic care model. The elements of the chronic care model include the design of service provision, decision support, the clinical information system, self-management support and community resources [16]. Some variables obtained from the external evaluation of the PMAQ-AB are contained in the elements of the chronic care model. Especially those related with actions for self-management support groups for NCDs, physical activity, activities in schools, registration of schoolchildren with health needs, health education, evaluation of user satisfaction, protocols, local health council and spaces of public participation, monitoring and analysis of indicators and health information, matrix support in the resolution of complex cases, specialized consultation scheduled, records of users and family.

After construction of the logical model, the model adequacy variables corresponding to the structure and process were selected in the PMAQ-AB database for state of Tocantins. Thus, the variables related to the primary care for NCDs in the FHS, according to the logical model, were collected. It was not possible to collect outcome variables directly related to users, such as blood glucose level or hypertension control. The outcome variables selected were those that demonstrated the level of organization of the work process of family health teams for tackling NCDs. The variables used in the study were constructed from two databases: a database with information on the infrastructure of the 233 PHUs responsible for the same ascribed population in the two cycles (2012 and 2014), and another with information on the work process of the 266 teams that operated in these 233 PHUs during the period.

The same variables of Cycle 1 and Cycle 2 were selected, and those common to the two cycles were used. In the variables with alterations in the categories of the responses, compatibilization was performed to be able to compare the cycles, excluding the variables that differed between them and excluding those that were not directly related to NCDs care and those with $10.0 \%$ or more missing data. A total of 55 variables of the PHUs structure were used for Cycle 1 of the PMAQ-AB, along with the corresponding ones present in Cycle 2, as well as 49 variables of the work process of the family health teams 


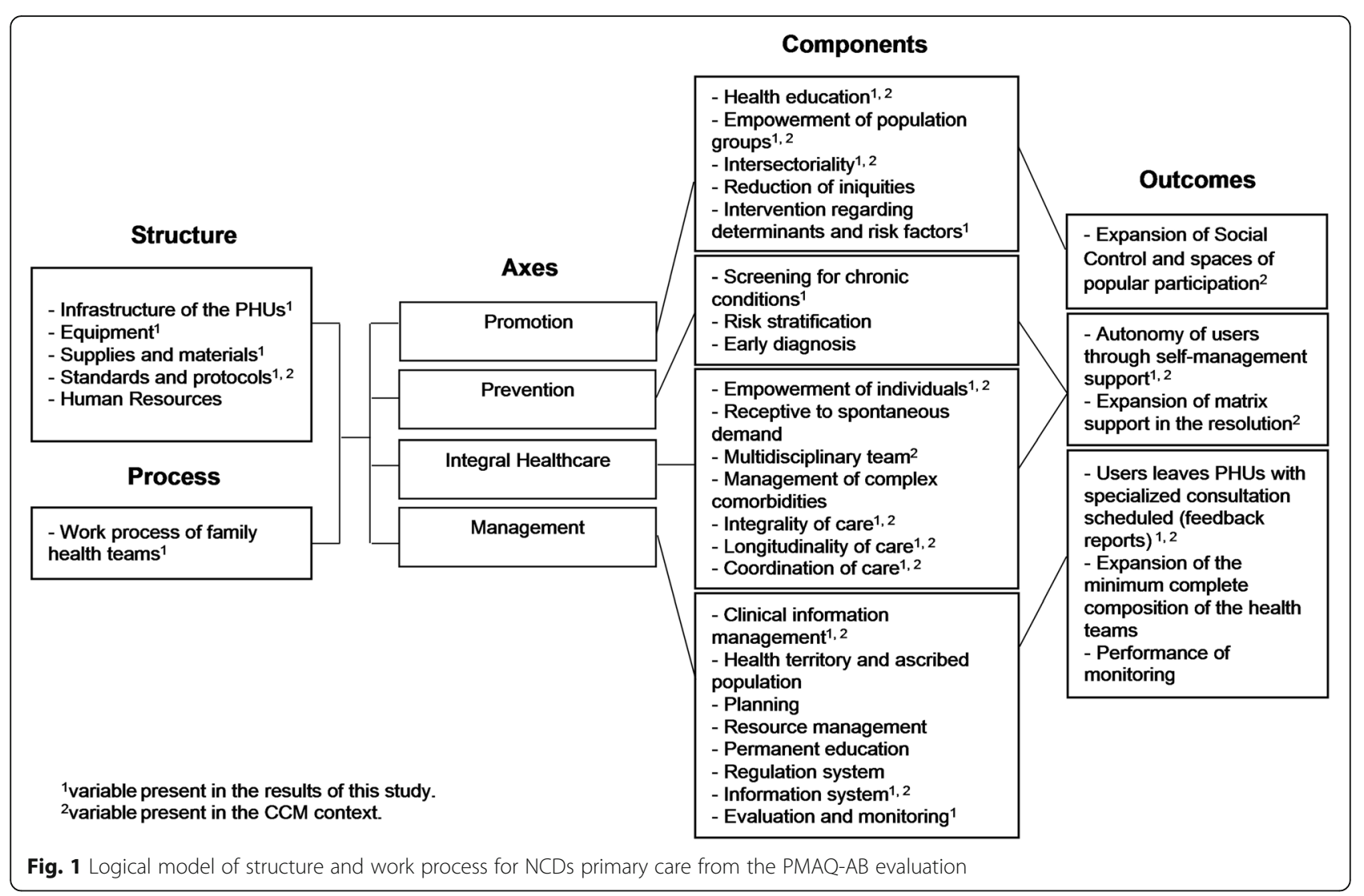

for the two cycles, resulting in a total of 104 variables in Cycle 1 and 104 variables in Cycle 2. The selected variables were, therefore, those that included the dimensions present in the logical model.

\section{Statistical analysis}

Initially, descriptive analysis by absolute $(n)$ and relative (\%) frequency was performed for each of the variables of the two cycles for the evaluation of consistency. The Principal Component Analysis for Categorical Data (CATPCA) technique was used to identify the variables or group of variables that best explained the variance of the original variables and reduce the variables for analysis of the variation between the two cycles of PMAQ$\mathrm{AB}[17,18]$. The CATPCA transforms qualitative variables into quantitative variables by means of a technique called optimal scaling, so that the transformation maximizes the responsible variance in the data set, thus creating a two-dimensional scale [19]. This technique is similar to nonlinear principal component analysis (NLPCA). The aim of this analysis was to reduce the number of variables without compromising the information necessary for the study $[17,18,20]$.

For CATPCA, a tetrachoric correlation matrix was first performed among all the variables of the model, which was used to conduct a factorial analysis of binary variables $[21,22]$. This type of correlation is indicated as a substitution for Pearson's correlation to investigate the bivariate relationship between two dichotomous variables [21-25]. Variables with correlation coefficients lower than $0.3\left(\mathrm{r}_{\mathrm{t}}<\right.$ 0.3 ) with any other variable of the matrix were excluded from the analysis. Next, multiple imputation of the missing values was carried out for each variable using the modal value of the respective variable [26]. To determine the number of principal components $(\mathrm{PC})$ to be extracted in the analysis, the eigenvalue criterion and Cronbach's alpha were used, and the extracted components were those that presented eigenvalues greater than $1[17,18$, 27] and presented Cronbach's alpha values greater than 0.6 as acceptable reliability [26]. Variables with a factor loading $\geq 0.4$ were considered to belong to each component $[17,18]$. Two CATPCA models were performed for the structure of PHUs (Cycles 1 and Cycle 2) and two models for the variables of the work process (Cycles 1 and Cycle 2). After extraction of the main components, box plot plots and descriptive analysis of the component scores were performed. Comparison of scores between the two cycles (Cycle 1 versus Cycle 2) was not possible due to differences in the retained variables and factor loadings in the CATPCA models of the two cycles. 
To analyze the adequacy of the FHS according to the primary care model for NCDs, the variables of the components from the CATPCA were used, and the framework of inference of adequacy proposed by Habicht et al. [28] was employed. Habicht's theoretical model of program/intervention evaluation is based on two axes of evaluation classification: intervention performance and impact. Both analyses are based on three type of inferences: adequacy, plausibility, and probability. For adequacy assessment, provision, coverage and impact indicators can be used. In the case of this study, the indicators of health service provision by the FHS were used. Comparison between the differences in the items of the variables retained in the CATPCA models (adequacy of the structure of the PHUs and adequacy of the work process) between Cycle 1 and Cycle 2 of the PMAQ-AB was carried out using the McNemar chi-squared statistical test for comparison of paired samples, considering a significance level of 5 and 95\% Confidence Interval [29]. The data were analyzed using the Statistical Package for the Social Sciences, version 24.0.

\section{Results}

\section{Descriptive analysis}

Additional file 1 shows the descriptive analysis of the 104 variables of Cycle 1 and the corresponding variables of Cycle 2 of the PMAQ-AB, which were used in this study to evaluate the adequacy of the structure and work process carried out in the FHS according to the primary care for NCDs and the changes that occurred between these two cycles in the state of Tocantins.

\section{PHUs analysis}

The CATPCA model for the structural variables of the 233 PHUs of Cycle 1 included 54 of the 55 variables initially investigated. One variable (nursing consultations) was excluded because it did not present any variation in values, impeding the tetrachoric correlation analysis. The other variables presented a correlation coefficient $\left(r_{t}\right) \geq 0.3$ with any other variable analyzed. Based on the eigenvalues, three PC were extracted from this analysis: PC1, PC2 and PC3. For Cycle 2, the CATPCA analysis included 54 of the 55 variables. One variable (table for clinical examination) was excluded because it did not present any variation. The other variables presented $a r_{t} \geq 0.3$ with any other variable analyzed. Based on the eigenvalues, three components also were extracted from this analysis: PC1, PC2 and PC3 (Additional file 2).

For Cycle 1, the PC1 could be interpreted as medications for the treatment of NCDs; the PC2 could be interpreted as materials for cervical cancer screening, and the PC3 could be interpreted as the provision of vaccinations and infrastructure. For Cycle 2, the variables that remained in the model were similar to those in Cycle 1 and received the same denominations as the Cycle 1 due to the similarity of the variables retained. The CATPCA summarized a set of 55 structural variables on a scale of 32 two-dimensional variables (24 Cycle 1 and Cycle 2; 3 only Cycle 1 , and 5 only Cycle 2) that could be used in the minimum evaluating of the structural adequacy of the PHUs for primary care for NCDs. Table 1 summarizes the variables explaining the PHUs structure belonging to Cycle 1 and Cycle 2 of the PMAQ-AB.

The variables extracted from the CATPCA explained the variability of the primary care for NCDs with respect to the structure of the PHUs, with the exception of standards and human resources that had no variables in the final CATPCA model, and the explanatory variables are the axes of the logical model (Fig. 1). Analysis of the adequacy of the structure of the PHUs (Table 2) identified a low proportion of dispensing of sufficient quantity of medications for the treatment of NCDs in Cycle 1 and Cycle 2. These medications were available in less than half of all PHUs evaluated. Only captopril showed a significant increase during the study period. There was a small but significant reduction in the materials for cervical cancer screening, although they are available in almost $90.0 \%$ of the PHUs. Seasonal influenza vaccination increased significantly and was available in $49.8 \%$ of the PHUs in Cycle 1 and $84.5 \%$ in Cycle 2 as well as the percentage of PHUs with sterilization room.

It is worth highlighting those variables that varied in the period, even though they were not retained in the same PCs for the same cycles. The variables procedures room, dressings room and inhalation room which also increased significantly in the period studied.

Additional file 2 and Additional file 4: Figure S1 show the descriptive analysis of scores extracted from CATPCA of the PHUs structure. The median scores of the components were: PC1 $(0.050-$ Cycle 1 and -0.485 - Cycle 2), PC2 (- 0.230 - Cycle 1 and 0.290 - Cycle 2) and PC3 (-0.120 - Cycle 1 and $0.080-$ Cycle 2).

\section{Work process analysis}

The CATPCA performed for the work process variables of the 266 health family teams of Cycle 1 and Cycle 2 included 49 investigative variables, all of which presented a correlation coefficient $\left(r_{t}\right) \geq 0.3$ with any other variable analyzed. According to the eigenvalue criterion $>1$ and Cronbach' alpha $\geq 0.6$, two components were extracted from the analysis of Cycle 1: PC1 and PC2. For Cycle 2, the results of the CATPCA model presented many differences in relation to Cycle 1 and also allowed the extraction of two components: PC1 and PC2 (Additional file 3).

For Cycle 1, the PC1 could be interpreted as health promotion and the PC2 could be health education for people with diabetes and hypertension. For Cycle 2, the PC1 could be interpreted as health promotion and 
Table 1 Factor loading of the PHUs structure. CATPCA model $(n=233)$

\begin{tabular}{|c|c|c|}
\hline \multirow[t]{2}{*}{ Principal Components } & Cycle 1 & Cycle 2 \\
\hline & \multicolumn{2}{|c|}{ Factor loading } \\
\hline \multicolumn{3}{|l|}{$\overline{P C 1}$} \\
\hline Medications for the treatment of NCDs & 0.797 & 0.638 \\
\hline Prednisone & 0.797 & 0.638 \\
\hline Salbutamol & 0.679 & 0.807 \\
\hline Ipratropium bromide & 0.678 & 0.804 \\
\hline Captopril & 0.439 & 0.900 \\
\hline Beta blockers & 0.816 & 0.936 \\
\hline Hydrochlorothiazide & 0.829 & 0.873 \\
\hline Losartan & 0.646 & 0.778 \\
\hline Simvastatin & 0.545 & 0.695 \\
\hline Glibenclamide & 0.881 & 0.876 \\
\hline Metformin & 0.830 & 0.895 \\
\hline $\mathrm{NPH}$ Insulin & 0.771 & 0.864 \\
\hline Regular Insulin & 0.735 & 0.814 \\
\hline Fenoterol & 0.714 & a \\
\hline Beclomethasone & a & 0.469 \\
\hline \multicolumn{3}{|l|}{ PC2 } \\
\hline \multicolumn{3}{|l|}{ Materials for cervical cancer screening } \\
\hline Speculum & 0.711 & 0.878 \\
\hline Endocervical brush & 0.770 & 0.844 \\
\hline Ayre spatula & 0.816 & 0.813 \\
\hline Slide clamp & 0.715 & 0.718 \\
\hline Glass blade with matte side & 0.653 & 0.692 \\
\hline Blade holder & 0.463 & 0.765 \\
\hline Gynecological table & 0.515 & a \\
\hline Light focuser & 0.435 & a \\
\hline Provide nursing consultations & a & 0.401 \\
\hline \multicolumn{3}{|l|}{ PC3 } \\
\hline \multicolumn{3}{|l|}{ Provision of vaccinations and infrastructure } \\
\hline Seasonal influenza vaccine & 0.400 & 0.519 \\
\hline Vaccination & 0.416 & 0.522 \\
\hline Vaccination room & 0.477 & 0.534 \\
\hline Sterilization room & 0.559 & 0.429 \\
\hline Team with Internet access & 0.433 & 0.418 \\
\hline Vehicle for external activities & 0.525 & 0.422 \\
\hline Procedures room & a & 0.509 \\
\hline Dressings room & a & 0.477 \\
\hline Inhalation room & a & 0.430 \\
\hline
\end{tabular}

Abbreviations: PHUs primary care units, NPH Neutral Protamine Hagedorn, $N C D$ s chronic noncommunicable diseases, $P C$ Principal Components Definitions of symbols: a factor loading $<0.4$, therefore, not extracted by the CATPCA model to integrate the components in this Cycle health site analysis and $\mathrm{PC} 1$ as health education and user referral. The CATPCA summarized a set of 49 variables related to the work process of the family health teams on a scale of 18 two-dimensional variables (only 6 variables common to Cycle 1 and Cycle 2; 5 only Cycle 1 and 7 only Cycle 2) - that can be used in the minimum evaluation of the work process of the teams regarding primary care for NCDs. Table 3 summarizes the explanatory variables of the work process of the family health teams belonging to Cycles 1 and Cycle 2 of the PMAQ-AB.

Analysis of the adequacy of the work process of the family health teams (Table 4 ) showed that of the 18 variables extracted from the CATPCA in at least one Cycle, 10 did not present a significant difference between Cycle 1 and Cycle 2 of the PMAQ-AB, which highlighted the significant increase in health promotion actions. The family health teams carried out more activities of health education for the ascribed population.

It is worth highlighting the variables that presented significant difference despite not being retained in the same PC. The variables health education for men, registration of schoolchildren with health needs for monitoring, evaluation of user satisfaction, health education schedule, incentive to physical activity and user receives referral form to seek scheduling were the actions that increased significantly during the study period. The variables health education for women, for the older adults and for addressing healthy eating were the actions that decreased significantly during that period.

Table 5 summarizes the variables that changed, those that increased and decreased the adequacy percentages, and those which did not change between 1 and Cycle 2 of PMAQ-AB.

Additional file 3 and Additional file 5: Figure S2 show the descriptive analysis of scores extracted from CATPCA of the work process of family health teams. The median scores of the components were: PC1 (0.165 - Cycle 1 and 0.171- Cycle 2) and PC2 (- $0.066-$ Cycle 1 and 0.063 - Cycle 2).

\section{Discussion}

The CATPCA results identified patterns (principal components - PC) for evaluating the adequacy of structure of PHUs and the work process of the family health teams in the primary care for NCDs in the state of Tocantins, Brazil. Three patterns were identified in the PHUs analysis and two patterns in the work process analysis of family health teams. These PC were composed of the variables that showed the greatest variability among the PHUs and among the teams evaluated, and those that better explained the variability in each PMAQ-AB cycle. However, it is important to highlight 
Table 2 Variation of structure variables of PHUs retained by the CATPCA according to the logical model $(n=233)$

\begin{tabular}{|c|c|c|c|c|c|c|c|}
\hline \multirow[t]{2}{*}{ Elements of logical model } & \multirow[t]{2}{*}{ Variables } & \multicolumn{2}{|c|}{ Cycle 1} & \multicolumn{2}{|c|}{ Cycle 2} & \multirow{2}{*}{$\begin{array}{l}\text { Variation } \\
\%(95 \% \text { Cl) }\end{array}$} & \multirow[t]{2}{*}{$p$-value } \\
\hline & & $n$ & $\%$ & $n$ & $\%$ & & \\
\hline & PC1 & & & & & & \\
\hline & Medications for the treatment of NCDs & & & & & & \\
\hline \multirow[t]{23}{*}{ Supplies and materials } & Prednisone & 102 & 43.8 & 58 & 24.9 & $-18.9(-27.1 ;-10.3)$ & $<0.001$ \\
\hline & Salbutamol & 81 & 34.8 & 78 & 33.5 & $-1.3(-9.8 ; 7.3)$ & 0.798 \\
\hline & Ipratropium bromide & 83 & 35.6 & 76 & 32.6 & $-3.0(-11.5 ; 5.6)$ & 0.457 \\
\hline & Captopril & 39 & 16.7 & 102 & 43.8 & $27.1(18.9 ; 34.7)$ & $<0.001$ \\
\hline & Beta blockers & 125 & 53.6 & 110 & 47.2 & $-6.4(-15.4 ; 2.6)$ & 0.096 \\
\hline & Hydrochlorothiazide & 122 & 52.4 & 93 & 39.9 & $-12.5(-21.2 ;-3.4)$ & 0.001 \\
\hline & Losartan & 69 & 29.6 & 76 & 32.6 & $3.0(-5.4 ; 11.4)$ & 0.500 \\
\hline & Simvastatin & 55 & 23.6 & 56 & 24.0 & $0.4(-7.3 ; 8.2)$ & 1.000 \\
\hline & Glibenclamide & 126 & 54.1 & 100 & 42.9 & $-11.2(-20.0 ;-2.1)$ & 0.002 \\
\hline & Metformin & 124 & 53.2 & 101 & 43.3 & $-9.9(-18.7 ;-0.8)$ & 0.010 \\
\hline & $\mathrm{NPH}$ Insulin & 90 & 38.6 & 92 & 39.5 & $0.9(-7.9 ; 9.6)$ & 0.896 \\
\hline & Regular Insulin & 82 & 35.2 & 83 & 35.6 & $0.4(-9.3 ; 8.2)$ & 1.000 \\
\hline & Fenoterol $^{a}$ & 87 & 37.3 & 20 & 8.6 & $-28.8(-35.8 ;-21.4)$ & 0.008 \\
\hline & Beclomethasone $^{b}$ & 22 & 9.4 & 31 & 13.3 & $3.9(-2.0 ; 9.7)$ & 0.149 \\
\hline & PC2 & & & & & & \\
\hline & Materials for cervical cancer screening & & & & & & \\
\hline & Speculum & 221 & 94.8 & 212 & 91.0 & $-3.8(-8.8 ; 0.9)$ & 0.093 \\
\hline & Provide nursing consultations ${ }^{\mathrm{b}}$ & 233 & 100.0 & 231 & 99.1 & $-0.9(-3.1 ; 0.9)$ & 0.500 \\
\hline & Endocervical brush & 221 & 94.8 & 207 & 88.8 & $-6.0(-11.2 ;-1.0)$ & 0.013 \\
\hline & Ayre spatula & 221 & 94.8 & 208 & 89.3 & $-5.5(-10.7 ;-0.6)$ & 0.019 \\
\hline & Slide clamp & 222 & 95.3 & 209 & 89.7 & $-5.6(-10.6 ;-0.8)$ & 0.019 \\
\hline & Glass blade with matte side & 220 & 94.4 & 211 & 90.6 & $-3.8(-9.2 ; 1.0)$ & 0.108 \\
\hline & Blade holder & 201 & 86.3 & 204 & 87.6 & $1.3(-4.9 ; 7.8)$ & 0.766 \\
\hline \multirow[t]{4}{*}{ Equipment } & Gynecological table ${ }^{a}$ & 222 & 95.3 & 225 & 96.6 & $1.3(-2.1 ; 4.7)$ & 0.969 \\
\hline & Light focuser ${ }^{a}$ & 220 & 94.4 & 224 & 96.1 & $1.7(-2.3 ; 5.9)$ & 0.861 \\
\hline & PC3 & & & & & & \\
\hline & Provision of vaccinations and infrastructure & & & & & & \\
\hline \multirow[t]{2}{*}{ Supplies and materials } & Seasonal influenza vaccine & 116 & 49.8 & 197 & 84.5 & $34.7(26.5 ; 42.3)$ & $<0.001$ \\
\hline & Provide vaccination & 220 & 94.4 & 216 & 92.7 & $-1.7(-6.4 ; 2.9)$ & 0.454 \\
\hline \multirow[t]{5}{*}{ Infrastructure } & Sterilization room & 114 & 48.9 & 166 & 71.2 & $22.3(13.5 ; 30.7)$ & $<0.001$ \\
\hline & Vaccination room & 212 & 91.0 & 208 & 89.3 & $-1.7(-7.3 ; 3.8)$ & 0.481 \\
\hline & Procedures room ${ }^{b}$ & 111 & 47.6 & 204 & 87.6 & $40.0(31.9 ; 47.2)$ & $<0.001$ \\
\hline & Dressings room ${ }^{b}$ & 168 & 72.1 & 210 & 90.1 & $18.3(11.0 ; 24.9)$ & 0.008 \\
\hline & Inhalation room ${ }^{\mathrm{b}}$ & 33 & 14.2 & 177 & 76.0 & $61.8(54.1 ; 68.2)$ & $<0.001$ \\
\hline \multirow[t]{2}{*}{ Equipment } & Team with Internet access & 104 & 44.6 & 108 & 46.4 & $1.8(-10.7 ; 7.3)$ & 0.659 \\
\hline & Vehicle for external activities & 140 & 60.1 & 128 & 54.9 & $-5.2(-14.0 ; 3.8)$ & 0.134 \\
\hline
\end{tabular}

Abbreviations: PHUs primary care units, $\mathrm{Cl}$ Confidence Interval, NPH Neutral Protamine Hagedorn, PC principal component

Definitions of symbols: ${ }^{\mathrm{a}}=$ Only Cycle $1 ;{ }^{\mathrm{b}}$ Only Cyle $2{ }^{\dagger}{ }^{\dagger}=\mathrm{McNemar}$ test

the need for further studies of this same methodology, which could vary for each Brazilian state.

The variables of the $\mathrm{PC}$ varied much more among the PHUs than among the teams, as observed from the high factor loadings found for the PHUs. In the analysis of PHUs, the three components obtained by the CATPCA (medications for the treat of NCDs, materials for cervical cancer screening, and provision of vaccinations and 
Table 3 Factor loading of the work process of the family health teams. CATPCA model $(n=266)$

\begin{tabular}{|c|c|}
\hline Principal Components & $\begin{array}{l}\text { Factor } \\
\text { loading }\end{array}$ \\
\hline \multicolumn{2}{|l|}{ Cycle 1} \\
\hline \multicolumn{2}{|l|}{ PC1 } \\
\hline \multicolumn{2}{|l|}{ Health promotion } \\
\hline Health education for women & 0.532 \\
\hline Health education for older adults & 0.595 \\
\hline Health education addressing healthy eating ${ }^{a}$ & 0.561 \\
\hline Health education for men & 0.472 \\
\hline $\begin{array}{l}\text { Document that proves the performance of health } \\
\text { education }\end{array}$ & 0.626 \\
\hline Registration of schoolchildren with health needs ${ }^{a}$ & 0.412 \\
\hline Evaluation of user satisfaction ${ }^{a}$ & 0.410 \\
\hline $\begin{array}{l}\text { Provide actions for groups of people with } \\
\text { hypertension }^{\mathrm{a}}\end{array}$ & 0.484 \\
\hline $\begin{array}{l}\text { Provide actions for groups of people with } \\
\text { diabetes }^{\mathrm{a}}\end{array}$ & 0.453 \\
\hline $\begin{array}{l}\text { Provide actions for groups of self-management } \\
\text { support for NCDs }\end{array}$ & 0.502 \\
\hline Registration of bedridden people $\mathrm{a}^{\mathrm{a}}$ & 0.416 \\
\hline \multicolumn{2}{|l|}{ PC2 } \\
\hline \multicolumn{2}{|c|}{ Health education for people with diabetes and hypertension } \\
\hline $\begin{array}{l}\text { Document that proves the performance of health } \\
\text { education }\end{array}$ & 0.431 \\
\hline $\begin{array}{l}\text { Provide actions for groups of people with } \\
\text { hypertension }\end{array}$ & 0.521 \\
\hline Provide actions for groups of people with diabetes & 0.459 \\
\hline \multicolumn{2}{|l|}{ Cycle 2} \\
\hline \multicolumn{2}{|l|}{ PC1 } \\
\hline \multicolumn{2}{|l|}{ Health promotion and health site analysis } \\
\hline Health education schedule & 0.400 \\
\hline Physical activities & 0.414 \\
\hline Registration of schoolchildren with health needs ${ }^{a}$ & 0.410 \\
\hline Evaluation of user satisfaction ${ }^{a}$ & 0.465 \\
\hline $\begin{array}{l}\text { Provide actions for women's groups (cancer } \\
\text { prevention) }\end{array}$ & 0.464 \\
\hline Provide actions for groups of people with obesity & 0.433 \\
\hline $\begin{array}{l}\text { Provide actions for groups of people with } \\
\text { hypertension }^{\mathrm{a}}\end{array}$ & 0.548 \\
\hline $\begin{array}{l}\text { Provide actions for groups of people with } \\
\text { diabetes }^{\mathrm{a}}\end{array}$ & 0.530 \\
\hline Protocol for priority home visits & 0.431 \\
\hline Registration of bedridden people ${ }^{a}$ & 0.531 \\
\hline $\begin{array}{l}\text { Management provides information for health } \\
\text { situation analysis }\end{array}$ & 0.474 \\
\hline \multicolumn{2}{|l|}{ PC2 } \\
\hline \multicolumn{2}{|l|}{ Health education and user referral } \\
\hline Health education addressing healthy eating ${ }^{a}$ & -0.407 \\
\hline
\end{tabular}

Table 3 Factor loading of the work process of the family health teams. CATPCA model $(n=266)$ (Continued)

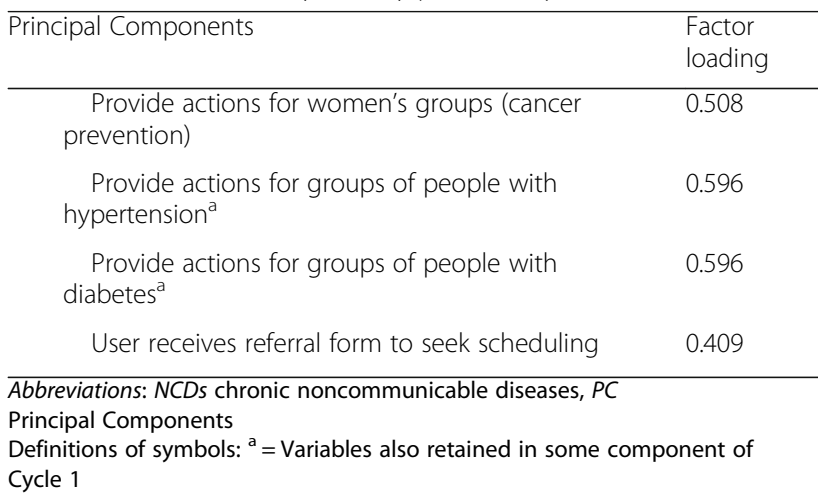

infrastructure) were similar for the two cycles, which favored the comparison among all of them in the assessment of adequacy. For the teams, two components were obtained by the CATPCA (health promotion and health education for people with diabetes and hypertension for Cycle 1 and health promotion and health site analysis and health education and user referral for Cycle 2), with different variables, if compared in one cycle and another. Variables related to prevention, integral health care and NCDs management, according to the logical model, did not remain in the final CATPCA model because they did not have a sufficient factorial load; therefore, they were not compared between Cycle 1 and Cycle 2 .

Evaluation of the structure of PHUs indicated the low availability of medications for the treatment of NCDs. The only structure variables that increased significantly in the studied period were the percentages of captopril and seasonal influenza vaccinations and the number of sterilization, procedures, dressings and inhalation rooms. The work process of family health teams showed significant improvement regarding health promotion activities.

Tocantins has the highest national coverage of the FHS [7], which is typical of underdeveloped regions such as the northern and northeastern regions of the country, where the Human Development Index (HDI), which is a proxy for socioeconomic conditions, is lower [30]. Increasing FHS coverage in these poorer regions, with the aim of reducing health inequities and increasing access to Primary Health Care [7], has not been sufficient to overcome the precarious conditions of the PHUs in these regions. They have the lowest scores of any region for infrastructure and lack consumables, medications and Information Technology (IT) equipment, such as computers and Internet access, with even worse findings for rural areas, indicating important social and structural inequalities in the municipalities [31], which it is not the case for the municipalities with lower FHS coverage that have a higher prevalence of adequate PHUs [32]. 
Table 4 Variation of variables of work process retained by the CATPCA according to the logical model $(n=266)$

\begin{tabular}{|c|c|c|c|c|c|c|c|}
\hline \multirow[t]{2}{*}{ Elements of the logical model } & \multirow[t]{2}{*}{ Variables } & \multicolumn{2}{|c|}{ Cycle 1} & \multicolumn{2}{|c|}{ Cycle 2} & \multirow{2}{*}{$\begin{array}{l}\text { Variation } \\
\%(95 \% \mathrm{Cl})\end{array}$} & \multirow{2}{*}{$\begin{array}{l}p^{-} \\
\text {value }^{\dagger}\end{array}$} \\
\hline & & $n$ & $\%$ & $\mathrm{n}$ & $\%$ & & \\
\hline \multirow[t]{6}{*}{ Health education } & Health education for women ${ }^{a}$ & 248 & 93.2 & 222 & 83.5 & $\begin{array}{l}-9.7(-15.3 ; \\
-4.4)\end{array}$ & 0.008 \\
\hline & Health education for older adults ${ }^{a}$ & 245 & 92.1 & 223 & 83.8 & $\begin{array}{l}-8.3(-13.9 ; \\
-2.8)\end{array}$ & 0.004 \\
\hline & Health education addressing healthy eating & 232 & 87.2 & 203 & 76.1 & $\begin{array}{l}-10.0(-17.4 ;- \\
4.4)\end{array}$ & 0.040 \\
\hline & Health education for men ${ }^{a}$ & 118 & 44.4 & 179 & 67.3 & $22.9(14.6 ; 30.9)$ & $\begin{array}{l}< \\
0.001\end{array}$ \\
\hline & $\begin{array}{l}\text { Document that proves the performance of health } \\
\text { education }^{a}\end{array}$ & 218 & 82.0 & 198 & 74.4 & $-7.5(-14.5 ; 0.5)$ & 0.426 \\
\hline & Health education schedule ${ }^{b}$ & 205 & 77.1 & 239 & 89.8 & $12.8(6.5 ; 19.0)$ & 0.002 \\
\hline Intersectoriality & Registration of schoolchildren with health needs & 62 & 23.3 & 92 & 34.6 & $11.3(3.6 ; 18.8)$ & 0.001 \\
\hline \multirow[t]{2}{*}{ Empowerment of individuals } & Evaluation of user satisfaction & 75 & 28.2 & 143 & 53.8 & $25.6(17.3 ; 33.3)$ & 0.001 \\
\hline & $\begin{array}{l}\text { Provide actions for groups of self-management sup- } \\
\text { port for } \mathrm{NCDs}^{\mathrm{a}}\end{array}$ & 169 & 63.5 & 169 & 63.5 & $0.0(-8.1 ; 8.1)$ & 0.849 \\
\hline Coordination of care & Registration of bedridden people & 117 & 44.0 & 132 & 49.6 & $5.6(-14.0 ; 2.8)$ & 0.159 \\
\hline \multirow{5}{*}{$\begin{array}{l}\text { Intervention regarding determinants and } \\
\text { risk factors }\end{array}$} & Provide actions for groups of people with diabetes & 251 & 94.4 & 244 & 91.7 & $-2.6(-7.1 ; 1.8)$ & 0.781 \\
\hline & Physical activities ${ }^{\mathrm{b}}$ & 136 & 51.1 & 187 & 70.3 & $19.2(18.6 ; 19.8)$ & $\begin{array}{l}< \\
0.001\end{array}$ \\
\hline & $\begin{array}{l}\text { Provide actions for women's groups (cancer } \\
\text { prevention) })^{b}\end{array}$ & 237 & 89.1 & 230 & 86.5 & $-2.6(-3.0 ; 8.3)$ & 0.425 \\
\hline & Provide actions for groups of people with obesity ${ }^{b}$ & 116 & 43.6 & 123 & 46.2 & $-2.6(-11.0 ; 5.9)$ & 1.000 \\
\hline & Protocol for priority home visits ${ }^{\mathrm{b}}$ & 100 & 37.6 & 98 & 36.8 & $-0.8(-8.9 ; 7.4)$ & 0.921 \\
\hline Clinical information management & $\begin{array}{l}\text { Management provides information for health situation } \\
\text { analysis }^{\mathrm{b}}\end{array}$ & 240 & 90.2 & 249 & 93.6 & $3.8(-1.3 ; 8.2)$ & 0.488 \\
\hline Integrality and Longitudinality of care & User receives referral form to seek scheduling ${ }^{b}$ & 113 & 42.5 & 142 & 53.4 & $10.9(2.4 ; 19.2)$ & 0.016 \\
\hline
\end{tabular}

The availability of medications for the treatment of NCDs in the PHUs in Tocantins is below $50.0 \%$ for all types of medication studied and falls far short of the $80.0 \%$ recommended by the World Health Organization [33], with insulin present in less than $40.0 \%$ of the PHUs. Studies evaluating the PHUs in the entire country have also demonstrated an availability of medications for the treatment of hypertension and diabetes below 50.0\% in Cycle 1 of the PMAQ-AB [34] and approximately $40.9 \%$ for the treatment of diabetes in Cycle 2 [32]. The free provision of medications for the treatment of NCDs has increased in the country since 2011 through the Popular Pharmacy Program and expanded the access of users [3]. However, several factors are related to adherence to treatment for hypertension and diabetes in Primary Health Care [35], including the proximity of the primary care source to the users of the health service, a conditional factor for people with diabetes who use insulin [36]. Furthermore, because Primary Health Care is well positioned to tackle NCDs as a gateway to the health system [37], the PHUs are care points that are strategically located close to the ascribed population and may promote greater access to medications for users with NCDs who attend the same primary care source over time.

Similarly, screening for cervical cancer can be carried out adequately and efficiently in PHUs [37]. The significant reduction of the screening materials identified in this study, despite having high availability in the PHUs of Tocantins, is worrying, since the maintenance of their adequacy over time is expected, especially considering that these materials are of low cost and low technological complexity. Similar studies have identified improvements in the quality of the screening due to the adequacy of the PHUs structure and the work process of the family health teams [38]. The adequacy of the PHUs structure across the country was of $50.0 \%$, with missed opportunities for screening occurring in the presence of persistent problems in the structure and work process [39]. It is likely that the high prevalence in the provision of these materials was induced by PMAQ-AB [11] because the Program guarantees greater financial resources 
Table 5 Description of the variables that increased, decreased, and did not change between PMAQ-AB Cycles

\begin{tabular}{|c|c|c|c|}
\hline \multirow[t]{2}{*}{ Dimensions of the FHS } & \multicolumn{3}{|l|}{ Variables } \\
\hline & Increased & Decreased & Did not change \\
\hline \multirow[t]{18}{*}{ Structure of PHUs } & Captopril & Prednisone & Salbutamol \\
\hline & Seasonal influenza vaccine & Hydrochlorothiazide & Ipratropium bromide \\
\hline & Sterilization room & Glibenclamide & Beta blockers \\
\hline & Procedures room & Metformin & Losartan \\
\hline & Dressings room & Fenoterol & Simvastatin \\
\hline & Inhalation room & Endocervical brush & NPH Insulin \\
\hline & & Ayre spatula & Regular Insulin \\
\hline & & Slide clamp & Beclomethasone \\
\hline & & & Speculum \\
\hline & & & Provide nursing consultations \\
\hline & & & Glass blade with matte side \\
\hline & & & Blade holder \\
\hline & & & Gynecological table \\
\hline & & & Light focuser \\
\hline & & & Provide vaccination \\
\hline & & & Vaccination room \\
\hline & & & Team with Internet access \\
\hline & & & Vehicle for external activities \\
\hline \multirow[t]{8}{*}{$\begin{array}{l}\text { Work process of family } \\
\text { health teams }\end{array}$} & Health education for men & Health education for women & $\begin{array}{l}\text { Document that proves the performance of } \\
\text { health education }\end{array}$ \\
\hline & Health education schedule & $\begin{array}{l}\text { Health education for older } \\
\text { adults }\end{array}$ & $\begin{array}{l}\text { Provide actions for groups of self-management } \\
\text { support for NCDs }\end{array}$ \\
\hline & $\begin{array}{l}\text { Registration of schoolchildren with } \\
\text { health needs }\end{array}$ & $\begin{array}{l}\text { Health education addressing } \\
\text { healthy eating }\end{array}$ & Registration of bedridden people \\
\hline & Evaluation of user satisfaction & & $\begin{array}{l}\text { Provide actions for groups of people with } \\
\text { diabetes }\end{array}$ \\
\hline & Physical activities & & $\begin{array}{l}\text { Provide actions for women's groups (cancer } \\
\text { prevention) }\end{array}$ \\
\hline & $\begin{array}{l}\text { User receives referral form to seek } \\
\text { scheduling }\end{array}$ & & $\begin{array}{l}\text { Provide actions for groups of people with } \\
\text { obesity }\end{array}$ \\
\hline & & & Protocol for priority home visits \\
\hline & & & $\begin{array}{l}\text { Management provides information for health } \\
\text { situation analysis }\end{array}$ \\
\hline
\end{tabular}

to the PHUs that present improvements in the structure and work process of family health teams. In addition, cervical cancer screening is a priority for FHS in the primary care context in Brazil [38, 39].

About PC3 (provision of vaccinations and infrastructure), the high rate of availability of the influenza vaccine in Tocantins is an important marker for the adequacy of the structure of the PHUs, since vaccinations against influenza and pneumonia have been shown to be effective in preventing complications and hospitalizations among users with chronic obstructive pulmonary disease [40]. The observation that the PHUs have a sufficient amount of available vaccines can be an important factor for high vaccination coverage in Tocantins. The state has one of the highest vaccination coverage rates in the country (89.1\%) according to findings from a similar study, which showed a national rate of $61.8 \%$ [41] and influenza vaccination coverage in priority groups exceeding 70\% between 2010 and 2012 [42]. International studies have reported lower influenza vaccination rates in a Primary Health Care service of the United States of America [43] and ones similar to those of Tocantins among users participating in a study performed in the city of Birmingham in the United Kingdom [44].

An improvement in the infrastructure of the PHUs in Tocantins can be considered, which increased the 
percentage of sterilization, procedures, dressings and inhalation rooms in the PHUs in Cycle 2 of the PMAQ$\mathrm{AB}$. Some national studies, using data from the PMAQ$A B$, related the improvement of the infrastructure of the PHUs to the increased proportion of some types of rooms to perform procedures and services for the users $[31,32,34]$. The improved infrastructure of the PHUs was probably driven by the increase in financing for construction and PHUs renovation through the PHUs Requalify Program [31], which began in 2010 throughout the country. In addition to the sterilization room, the findings of this study highlighted other important variables that did not present a significant difference in the period but were in the final CATPCA model, such as the vaccination room and provide vaccination, which are considered to be quality markers of the PHUs structure in the country [31]. This important result found in the statistical approach used in this study that can be useful to evaluate the adequacy of structure in other contexts.

Despite an absence of significant differences in the period under study, lack of Internet access for just under $50.0 \%$ of the family health teams in the PHUs investigated is worrisome, as there is evidence confirming positive results from the use of IT in primary care for NCDs. Overall, this finding reflects the incipient process of IT incorporation into Primary Health Care in Brazil in terms of structure, with $41.9 \%$ of the family health teams working in contexts that present low levels of IT [45]. The use of IT is fundamental in redesigning the primary care model for NCDs, especially considering its contribution to decision support and the implementation of clinical information systems [46]. The implementation is mainly carried out through records and adherence to clinical protocols [47] and it is fundamental for improving the performance of the health system. In a study carried out in 22 European countries, the need to improve the information infrastructure in the Primary Health Care of the countries was highlighted to achieve these objectives [48]. Strategies such as the use of reminders regarding medication treatment [35] and provision of the influenza vaccination [49] through interactive voice response (IVR) have proven to be positive. Furthermore, there is an association between IT incorporation and quality of care by family health teams, with better quality certification results in the PMAQ-AB [45].

Although the analysis of the work process of family health teams did not result in PCs with equal variables between cycles, as it happened in the PHUs analysis, it is worth highlighting those variables that showed significant differences in adequacy between Cycle 1 and Cycle 2 of PMAQ-AB. Analysis of the work process indicated health promotion as a key point in the work of these teams. The variables that significantly increased beetwen cycles were health education for men, registration of schoolchildren with health needs, evaluation of user satisfaction, health education schedule and physical activities and user receives referral form to seek scheduling.

These findings assume that family health teams are seeking to create greater links with the community through activities performed outside the PHUs environment, especially as schoolchildren were the target of the actions of one third of the teams in Cycle 2. This finding may be related to the advances of the School Health Program in 2008 [50], which encouraged health teams to visit schools and carry out health promotion activities among schoolchildren.

In a similar study using the PMAQ-AB, the data did not differ significantly from the findings of the present study. The majority of the family health teams reported carrying out health promotion actions, such as school activities and physical activity [51]. The findings of this study regarding health promotion are consistent with results from other studies in which health promotion was also identified as an important strategy in chronic care model evaluation contexts, with improvements in health education processes [52], physical activity [53] and satisfaction of the users [54]. Brazilian studies evaluating the chronic care model in the FHS identified improvements in links with the community [55] and positive changes in the care performed by the teams [56].

Regarding health education, the findings of this study do not allow an evaluation of the nature of the health education carried out by the teams. It is not known whether these actions involved potent educational processes to encourage the change of behavior of the users or merely informed them about the damage of certain habits that are harmful to health. It is known that the health education and health promotion programs offered in PHUs are directed more toward adults and elderly individuals, usually users with hypertension and diabetes [57], which justifies the high percentage of health teams developing activities for these groups in Tocantins in the two cycles of the PMAQ-AB. Furthermore, based on the National Health Survey (Pesquisa Nacional de Saúde), more than $80.0 \%$ of users with hypertension and diabetes who used public or private health services were given advice regarding adequate diet, body weight and the practice of physical activity. However, adherence to beneficial practices such as healthy eating and physical activity was not greater among these users, although they prioritized avoiding certain harmful habits, such as the use of tobacco products. This finding showed that these specific groups preferred to avoid harmful habits than to adhere to healthy practices [58].

The variables of health education for women, for older adults and for addressing healthy were those that decreased in the period. It is likely that family health teams 
have performed fewer health education actions for those ones in order to have more time to target these actions to men users. Historically, Primary Health Care in Brazil has been little directed to men's health, with greater coverage for children, women and the elderly [59, 60]. The increase in health education for men may be an indicator of improved access for this population to the FHS.

The variable user receives referral form to seek scheduling is an important variable related to care coordination, which can become more effective when access to scheduling is guaranteed, even if scheduled by the user himself or by the PHUs. It is known that referral of users can be more effective if requested by family health teams and if the waiting time of the user to schedule appointments or specialized exams is shorter as possible [9].

Even though there was no significant difference between the PMAQ-AB cycles, self-management support is an important variable for evaluating the adequacy of the primary care for NCDs. However, this variable was not performed by almost $40.0 \%$ of the family health teams in the two PMAQ-AB cycles. Self-management support is one of the key components of the chronic care model that aims to improve chronic care in the Primary Health Care and to contribute to the redesign of health systems aimed at NCDs [60].

This study did not intend to investigate the possible interactions between structure and process to achieve expected outcomes in relation to the primary care model for NCDs. However, the adequacy of the structure is an element that contributes in favor of the work process of the family health teams in their various work contexts. According to the Donabedian quality evaluation model, a good structure increases the likelihood of a good process, which in turn increases the likelihood of a good result [14]. A study in South Africa found that, regardless of structure, a good process mediated the relationship between a good structure and a good outcome in the Primary Health Care model in South Africa [61]. In fact, PHUs with significant structural deficiencies make it difficult to retain professionals in the work process of the family health teams [62, 63]. Furthermore, the final analysis showed that the deficiencies can make it impossible to implement the necessary advances in the primary care model, with an emphasis on NCDs.

There are a number of limitations to this study. Of particular concern was that the database consisted of secondary data and there were too many variables to choose for the study. The variable human resource was excluded because it presented a high percentual of missing data. This study prioritized those variables according to the theoretical framework for primary care for NCDs, and systematized them in the logical model. In addition, it was not possible to collect outcome variables directly related to the user because they are not available in database. It was not possible to evaluate the adequacy of the FHS as a whole and make inferences about it due to lack of outcome variables directly related to the user. However, it was possible to evaluate in this study the adequacy of the structure and work process of family health teams to primary care for NCDs in the high coverage context of the FHS. Nevertheless, the PMAQ$\mathrm{AB}$ database is currently the largest national FHS database and it has great potential for use in primary care evaluation research. Furthermore, PMAQ-AB is a program with voluntary adherence linked to financial incentive, which makes it possible that the teams that adhered were those with the best performance. There was a change in the external evaluation instrument, reducing the data analysis to the variables belonging to the two PMAQ-AB cycles. Moreover, the comparison between Cycles 1 and Cycle 2 in this study caused information losses related to those that did not participate in the two cycles. But this was minimized by the fact that Tocantins presented one of the highest rates of adherence to the Program in the country, encompassing almost all the PHUs and family health teams of the state.

Although some studies have used data from PMAQ$\mathrm{AB}[31,32,34,38,39,41,45,51,53,59]$, this is the first one that evaluated the structure of PHUs and the work process of family health teams for NCDs primary care using the CATPCA method. This approach was chosen because the PMAQ-AB data is categorical and a method was needed to reduce a large number of variables and identify the most powerful indicators explaining the variability of variables between PMAQ-AB cycles.

The PMAQ-AB may have led to improvements in the overall organization of the work process of the family health teams included in this study, especially regarding health promotion. However, more significant process changes may require additional time for evaluation, and further studies are needed incorporating data from the new PMAQ-AB cycles.

\section{Conclusions}

The improvement of the PHUs infrastructure may have been important in the provision of rooms, influenza vaccine and materials for cervical cancer screening. However, the low supply of medicines undoubtedly constitutes an important barrier to be overcome in the FHS. The health promotion, especially health education actions and physical activity promotion, were the main work tools of family health teams. The family health teams need to expand their health promotion actions with greater emphasis on intersectoral actions beyond those carried out at school activities.

The structure of PHUs and the work process of family health teams have low adequacy, that is, they do not 
have enough power to tackle chronic diseases in the FHS. This low adequacy was due to the following problems: low availability of medicines for NCD, low use and access to IT, lack of substantial intersectoral actions of health promotion, fragile integrality and longitudinality of care regarding referral of users to experts and low actions for empowerment of the users through selfmanagement support. All these variables have great potential for evaluating primary care for NCDs because they were widely used in studies that evaluated CCM.

The methodology and results of this study can be useful to improve the data collection instrument of PMAQ$A B$. It can orient the revision of which variables should remain, be introduced or withdrawn in the PMAQ-AB questionaire and which ones better capture the care model for NCDs. Finally, the methodology used may support the Brazilian Ministry of Health in reviewing the PMAQ-AB data collection instrument, making it more powerful to evaluate the primary care model for NCDs implemented in the municipalities. And more importantly, can identify the limitations of the care model implemented by the FHS and support it in implementing actions that strengthen NCDs care in the territory where they operate.

\section{Supplementary information}

Supplementary information accompanies this paper at https://doi.org/10. 1186/s12913-019-4737-2.

Additional file 1. Description of the variables of the PHUs $(n=233)$ and the family health teams $(n=266)$.

Additional file 2. Factor loading of the variables of the PHUs structure.

Additional file 3. Factor loading of the variables of the work process of family health teams.

Additional file 4: Figure S1. Descriptive analysis of principal component scores between Cycles 1 and 2 for PHUs. Definitions of abbreviations: PHUs: primary care units; PC1: Medications for the treatment of NCDs; PC2: Materials for cervical cancer screening; PC3: Provision of vaccinations and infrastructure.

Additional file 5: Figure S2. Descriptive analysis of principal component scores between Cycles 1 and 2 for family health teams. Definitions of abbreviations: Cycle 1 - PC1: Health Promotion; PC2: Care for groups with diabetes and hypertension; Cycle 2 - PC1: Health promotion and health site analysis; PC2: Health education and user referral.

\section{Abbreviations \\ CATPCA: Principal Component Analysis for Categorical Data; FHS: Family Health Strategy; IT: Information Technology; NCDs: Chronic noncommunicable diseases; PC: Principal component; PHUs: Primary Health Units; PMAQ-AB: National Program for Improving Access and Quality of Primary Care (Programa Nacional de Melhoria do Acesso e da Qualidade da Atenção Básica)}

\section{Acknowledgements}

Special thanks to the Primary Care Department (Departamento de Atenção Básica - DAB) of the Ministry of Health and the Fiocruz - Rio de Janeiro, Brazil, for assistance with the survey data.

\section{Authors' contributions}

KCGA conceived of and designed the study, oversaw study implementation, analyzed the data, interpretation of the findings and drafted and revised the manuscript. RGA contributed to the analyzed the data and interpretation of the findings, and critically reviewed the manuscript. MRS contributed to the study design, interpretation of the findings and critically reviewed the manuscript. OLMN contributed to the study design, the analyzed the data and interpretation of the findings, and critically reviewed the manuscript. All authors read and approved the final manuscript.

\section{Authors' information}

KCGA is a student of postgraduate in the Institute of Tropical Pathology and Public Health, Federal University of Goiás, Goiânia, Goiás, Brazil. She also is a nurse and Professor in the Department of Medicine at the Federal University of Tocantins. KCGA contributed as the local coordinator of PMAQ-AB data collection in Cycle 1 and Cycle 2. OLMN and MRS are professors of the Department of Public Health of the Institute of Pathology and Tropical Medicine of the Federal University of Goiás, Brazil. They are researchers in the area of chronic diseases.

\section{Funding}

Not applicable.

\section{Availability of data and materials}

The datasets analysed during the current study are available in the Departament of Primary Care (Departamento de Atenção Básica - DAB) repository, https://aps.saude. gov.br/ape/pmaq. To select data from sctructure of primary health units: 1. Select Ciclo 1 [Portuguese]; 2. Select Microdados da avaliação Externa [Portuguese]; 3. Then choose Módulo I UBS [Portuguese]; 4. Finally, choose UBS Tocantins [Portuguese]. Do it the same for Ciclo 2 [Portuguese] to download the dataset. To select data from family health strategy teams: 1 . Select Ciclo 1 [Portuguese]; 2. Select Microdados da avaliação Externa [Portuguese]; 3. Then, choose Módulo II Equipe [Portuguese]; 4. Finally, choose Equipe Tocantins [Portuguese]. Do it the same for Ciclo 2 [Portuguese] to download the dataset.

Ethics approval and consent to participate Not applicable.

\section{Consent for publication}

Not applicable.

\section{Competing interests}

The authors declare that they have no competing interests.

Received: 28 March 2019 Accepted: 12 November 2019

Published online: 29 November 2019

\section{References}

1. World health statistics 2018. Monitoring health for the SDG's, sustainable development goals. Geneva: World Health Organization; 2018. Available from: https://www.who.int/gho/publications/world_health_statistics/2018/ en/. Accessed 05 Feb 2019

2. Malta DC, França E, Abreu DMX, Perillo RD, Salmen MC, Teixeira RA, et al. Mortality due to noncommunicable diseases in Brazil, 1990 to 2015, according to estimates from the global burden of disease study. Sao Paulo Med J. 2017;135:213-21.

3. Schmidt MI, Duncan BB, Silva GAE, Menezes AM, Monteiro CA, Barreto SM, et al. Chronic non-communicable diseases in Brazil: burden and current challenges. Lancet. 2011;377:1949-61.

4. Malta DC, Stopa SR, Szwarcwald CL, Gomes NL, Silva JB, Dos Reis AA. Surveillance and monitoring of major chronic diseases in Brazil - national health survey, 2013. Rev Bras Epidemiol. 2015:18:3-16.

5. World Health Organization. Global action plan for the prevention and control of noncommunicable diseases 2013-2020. Geneva: World Health Organization; 2013. Available from: https://www.who.int/nmh/events/ncd action_plan/en/. Accessed 12 Jun 2018

6. Ministry of Health. Ordinance 2.436, 21 September 2017, Brasília, Brazil 2017. Available from: http://bvsms.saude.gov.br/bvs/saudelegis/gm/2017/ prt2436_22_09_2017.html. Accessed 05 Mar 2018. 
7. Malta DC, Santos MA, Stopa SR, Vieira JE, Melo EA, dos Reis AA. Family health strategy coverage in Brazil, according to the national health survey, 2013. Cien Saude Colet. 2016;21:327-38.

8. Malta DC, Neto OLDM, Silva JBD. Presentation of the strategic action plan for coping with chronic diseases in Brazil from 2011 to 2022. Epidemiol e Serviços Saúde. 2011;20:425-38.

9. Paim J, Travassos C, Almeida C, Bahia L, Macinko J. The Brazilian health system: history, advances, and challenges. Lancet. 2011;377:1778-97.

10. Pinto HA, Sousa ANAD, Ferla AA. The National Program for access and quality improvement in primary care: faces of an innovative policy. Saúde em Debate. 2014;38:358-72.

11. Ministry of Health. Programme for improving access and quality of primary care (PMAQ-AB): instruction manual [Portuguese], Brasília, Brazil. 2017. Available from: http://189.28.128.100/dab/docs/portaldab/documentos/ Manual_Instrutivo_3_Ciclo_PMAQ.pdf. Accessed 15 Jul 2018.

12. Wagner $\mathrm{EH}$. Chronic disease management: what will it take to improve care for chronic illness? Eff Clin Pract. 1998:1:2-4.

13. Department of Basic Attention. E-primary care manager. Information and management of primary care. Brasília, Brazil. 2014. Available from: https:// egestorab.saude.gov.br/paginas/acessoPublico/relatorios/ relHistoricoCoberturaAB.xhtml. Accessed 13 Jul 2018.

14. Donabedian A. The quality of care. JAMA. 1988;260:1743.

15. Hartz Z, da Silva L. Avaliação em saúde: dos modelos teóricos à prática na avaliação de programas e sistemas de saúde. Rio de Janeiro: Editora FIOCRUZ; 2006. Available from: http://books.scielo.org/id/xzdnf/pdf/hartz9788575415160.pdf. Accessed 11 Feb 2018

16. Bonomi AE, Wagner EH, Glasgow RE, VonKorff M. Assessment of chronic illness care (ACIC): a practical tool to measure quality improvement. Health Serv Res. 2002;37:791-820.

17. Linting $M$, van der Kooij A. Nonlinear principal components analysis with CATPCA: a tutorial. J Pers Assess. 2012;94:12-25.

18. Linting M, Meulman JJ, Groenen PJ, van der Koojj AJ. Nonlinear principal components analysis: introduction and application. Psychol Methods. 2007; 12:336-58.

19. Tosto G, Monsell SE, Hawes SE, Mayeux R. Pattern of extrapyramidal signs in Alzheimer's disease. J Neurol. 2015:262:2548-56.

20. Young $H$, Burke L, Gabhainn SN. Sexual intercourse, age of initiation and contraception among adolescents in Ireland: findings from the health behaviour in school-aged children (HBSC) Ireland study. BMC Public Health. 2018;18:362.

21. Jöreskog KG. On the estimation of polychoric correlations and their asymptotic covariance matrix. Psychometrika. 1994;59:381-9.

22. Savalei $V$, Bonett DG, Bentler PM. CFA with binary variables in small samples: a comparison of two methods. Front Psychol. 2014;5:1515.

23. Debelak R, Tran US. Comparing the effects of different smoothing algorithms on the assessment of dimensionality of ordered categorical items with parallel analysis. PLoS One. 2016;11:e0148143.

24. Rzewuska M, de Azevedo-Marques JM, Coxon D, Zanetti ML, Zanetti AC, Franco $\sqcup$, et al. Epidemiology of multimorbidity within the Brazilian adult general population: evidence from the 2013 National Health Survey (PNS 2013). PLoS One. 2017:12:e0171813.

25. Tran US, Formann AK. Performance of parallel analysis in retrieving unidimensionality in the presence of binary data. Educ Psychol Meas. 2008; 69:50-61.

26. Zhang Z. Missing data imputation: focusing on single imputation. Ann Transl Med. 2016:4:9

27. Cattell RB. The scree test for the number of factors. Multivariate Behav Res. 1966;1:245-76

28. Habicht JP, Victora CG, Vaughan JP. Evaluation designs for adequacy, plausibility and probability of public health programme performance and impact. Int J Epidemiol. 1999:28:10-8.

29. Newcombe RG. Interval estimation for the difference between independent proportions: comparison of eleven methods. Stat Med. 1998;17:873-90.

30. Soares JJN, Machado MH, Alves CB. The mais medicos (more doctors) program, the infrastructure of primary health units and the municipal human development index. Cien Saude Colet. 2016;21:2709-18.

31. Bousquat A, Giovanella L, Fausto MCR, Fusaro ER, Mendonça MHMD, Gagno J, et al. Structural typology of Brazilian primary healthcare units: the 5 Rs. Cad Saude Publica. 2017;33:1-15 Accessed 12 Oct 2018.

32. Neves RG, Duro SMS, Muniz J, Castro TRP, Facchini LA, Tomasi E. Structure of primary healthcare units for treating persons with diabetes: cycles I and II of the Brazilian national program to improve access and quality. Cad Saude Publica. 2018:34:e00072317.

33. World Health Organization. Essential medicines and basic health technologies for noncommunicable diseases: towards a set of actions to improve equitable access in member states. Geneva; 2015. Available from: https://www.who.int/nmh/ncd-tools/targets/Final_medicines_and_ technologies_02_07_2015.pdf. Accessed 20 Feb 2018

34. Mendes LV, Campos MR, Chaves GC, Silva RMD, Freitas PDS, Costa KS, et al. Availability of medicines in primary health care facilities and related factors: a cross sectional approach. Saúde Em Debate. 2014;38:109-23.

35. Kassavou A, Sutton S. Reasons for non-adherence to cardiometabolic medications, and acceptability of an interactive voice response intervention in patients with hypertension and type 2 diabetes in primary care: a qualitative study. BMJ Open. 2017;7:e015597.

36. Littenberg B, Strauss K, MacLean CD, Troy AR. The use of insulin declines as patients live farther from their source of care: results of a survey of adults with type 2 diabetes. BMC Public Health. 2006:6:198.

37. Kruk ME, Nigenda G, Knaul FM. Redesigning primary care to tackle the global epidemic of noncommunicable disease. Am J Public Health. 2015; 105:431-7.

38. Barcelos MRB, Lima RDCD, Tomasi E, Nunes BP, Duro SMS, Facchini LA. Quality of cervical cancer screening in Brazil: external assessment of the PMAQ. Rev Saude Publica. 2017;51:67.

39. Tomasi E, Oliveira TF, Fernandes PAA, Thumé E, Silveira DSD, Siqueira FV, et al. Structure and work process in the prevention of cervical cancer in health basic attention in Brazil: program for the improvement of access and quality. Rev Bras Saúde Matern Infant. 2015;15:171-80.

40. Cimen P, Unlu M, Kirakli C, Katgi N, Ucsular FD, Ayranci A, et al. Should patients with COPD be vaccinated? Respir Care. 2015;60:239-43.

41. Pocas KC, Freitas LRS, Duarte EC. Census of the primary health care structure in Brazil (2012): potential coverage estimates. Epidemiol Serv Saude. 2017;26: $275-84$

42. Luna EJDA, Gattás VL, Campos SRDSL. Effectiveness of the Brazilian influenza vaccination policy: a systematic review. Epidemiol Serv Saúde. 2014;23:559-75

43. Agarwal A, Zhang W, Kuo Y, Sharma G. Process and outcome measures among COPD patients with a hospitalization cared for by an advance practice provider or primary care physician. PLoS One. 2016;11:e0148522.

44. Khan A, Dickens AP, Adab P, Jordan RE. Self-management behaviour and support among primary care COPD patients: cross-sectional analysis of data from the Birmingham chronic obstructive pulmonary disease cohort. NPJ Prim Care Respir Med. 2017;27:46.

45. Santos ADFD, Sobrinho DF, Araujo LL, Procópio CDSD, Lopes ÉAS, Lima AMDLDD, et al. Incorporation of information and communication technologies and quality of primary healthcare in Brazil. Cad Saude Publica. 2017;33:1-14.

46. Bodenheimer T, Wagner EH, Grumbach K. Improving primary care for patients with chronic illness: the chronic care model, part 2. JAMA. 2002; 288:1909-14.

47. Hoque DME, Kumari V, Hoque M, Ruseckaite R, Romero L, Evans SM. Impact of clinical registries on quality of patient care and clinical outcomes: a systematic review. PLoS One. 2017;12:e0183667.

48. Pelone F, Kringos DS, Spreeuwenberg P, De Belvis AG, Groenewegen PP. How to achieve optimal organization of primary care service delivery at system level: lessons from Europe. Int J Qual Health Care. 2013;25:381-93.

49. Shoup JA, Madrid C, Koehler C, Lamb C, Ellis J, Ritzwoller DP, et al. Effectiveness and cost of influenza vaccine reminders for adults with asthma or chronic obstructive pulmonary disease. Am J Manag Care. 2015; 21:e405-13.

50. Malta DC, Oliveira TP, Santos MA, Andrade SS, Silva MM. Progress with the strategic action plan for tackling chronic non-communicable diseases in Brazil, 2011-2015. Epidemiol Serv Saude. 2016:25:373-90.

51. Medina M, Aquino R, Vilasbôas A, Mota E, Pinto E, Luz L, et al. Health promotion and chronic disease prevention: what are family health teams doing? Saúde Em Debate. 2014;38:69-82.

52. Bowen JL, Provost L, Stevens DP, Johnson JK, Woods DM, Sixta CS, et al. Assessing chronic illness care education (ACIC-E): a tool for tracking educational re-design for improving chronic care education. J Gen Intern Med. 2010;25:S593-609.

53. Glasgow RE, Whitesides $H$, Nelson CC, King DK. Use of the patient assessment of chronic illness care (PACIC) with diabetic patients: 
relationship to patient characteristics, receipt of care, and self-management. Diabetes Care. 2005;28:2655-61.

54. Stock S, Pitcavage JM, Simic D, Altin S, Graf C, Feng W, et al. Chronic care model strategies in the United States and Germany deliver patientcentered, high-quality diabetes care. Health Aff (Millwood). 2014;33:1540-8.

55. Schwab GL, Moysés ST, Kusma SZ, Ignácio SA, Moysés SJ. Perception of innovations in chronic diseases/conditions'care: an evaluative research in Curitiba. Saúde Em Debate. 2014;38:307-18.

56. Costa KCD, Cazola LHDO, Tamaki EM. Assessment of chronic illness care (ACIC): avaliação da aplicabilidade e resultados. Saúde Em Debate. 2016;40:106-17.

57. Sá GBARD, Dornelles GC, Cruz KG, Amorim RCDA, Andrade SSCDA, Oliveira TP, et al. The health academy program as a strategy to promote health and healthy lifestyle: the national implementation scenario. Cien Saude Colet. 2016;21:1849-60.

58. Szwarcwald CL, de Souza-Júnior PRB, Damacena GN, Almeida WDSD, Malta DC, Stopa SR, et al. Recommendations and practice of healthy behaviors among patients with diagnosis and diabetes in Brazil: National Health Survey (PNS), 2013. Rev Bras Epidemiol. 2015;18:132-45.

59. Kessler M, Thumé E, Duro SMS, Tomasi E, Siqueira FCV, Silveira DS, et al. Health education and promotion actions among teams of the National Primary Care Access and quality improvement program, Rio Grande do Sul state. Brazil Epidemiol Serv Saúde. 2018;27:1-12.

60. Bodenheimer T, Wagner EH, Grumbach K. Improving primary care for patients with chronic illness. JAMA. 2002;288:1775-9.

61. Ameh S, Gomez-Olive FX, Kahn K, Tollman SM, Klipstein-Grobusch K. Relationships between structure, process and outcome to assess quality of integrated chronic disease management in a rural south African setting: applying a structural equation model. BMC Health Serv Res. 2017;17:229.

62. Giovanella L, Mendonca MH, Fausto MC, Almeida PF, Bousquat A, Lima JG, et al. Emergency supply of doctors by the mais medicos (more doctors) program and the quality of the structure of primary health care facilities. Cien Saude Colet. 2016;21:2697-708.

63. Garnelo L, Lucas A, Parente R, Rocha E, Gonçalves M. Organization of health care for chronic conditions by family health teams in the Amazon. Saúde Em Debate. 2014;38:158-72.

\section{Publisher's Note}

Springer Nature remains neutral with regard to jurisdictional claims in published maps and institutional affiliations.

Ready to submit your research? Choose BMC and benefit from:

- fast, convenient online submission

- thorough peer review by experienced researchers in your field

- rapid publication on acceptance

- support for research data, including large and complex data types

- gold Open Access which fosters wider collaboration and increased citations

- maximum visibility for your research: over $100 \mathrm{M}$ website views per year

At BMC, research is always in progress.

Learn more biomedcentral.com/submissions 